\title{
Transferability of Military-Specific Cognitive Research to Military Training and Operations
}

\author{
Christopher A. J. Vine ${ }^{1 *}$, Stephen D. Myers ${ }^{1}$, Sarah L. Coakley ${ }^{1,2}$, Sam D. Blacker ${ }^{1}$ and \\ Oliver R. Runswick ${ }^{1,3}$ \\ ${ }^{1}$ Occupational Performance Research Group, Institute of Sport, University of Chichester, Chichester, United Kingdom, \\ ${ }^{2}$ Faculty of Sport, Allied Health and Performance Science, St Mary's University, Twickenham, London, United Kingdom, \\ ${ }^{3}$ Department of Psychology, Institute of Psychiatry, Psychology \& Neuroscience, Kings College London, London, \\ United Kingdom
}

Keywords: occupation, environment, representative design, external validity, soldier, combat

\section{INTRODUCTION}

The influence of acute aerobic exercise on cognitive function is well documented (e.g., Lambourne and Tomporowski, 2010; Chang et al., 2012). However, the influence of military specific exercise on aspects of cognitive function relevant to military operations is less well understood. With the increasing physical and cognitive loads placed on military personnel (Mahoney et al., 2007), this interaction is fundamental to understanding operational performance (Russo et al., 2005). As such, ensuring the transferability of military-specific cognitive research to military training

OPEN ACCESS

Edited by:

Hui Chen,

Zhejiang University, China

Reviewed by:

Kristy Martin,

University of Canberra, Australia

${ }^{*}$ Correspondence:

Christopher A. J. Vine

c.vine@chi.ac.uk

Specialty section: This article was submitted to

Cognitive Science,

a section of the journal

Frontiers in Psychology

Received: 11 September 2020 Accepted: 28 January 2021

Published: 18 February 2021

Citation:

Vine CAJ, Myers SD, Coakley SL, Blacker SD and Runswick OR (2021)

Transferability of Military-Specific Cognitive Research to Military Training and Operations.

Front. Psychol. 12:604803. doi: 10.3389/fpsyg.2021.604803 and operations, is of great importance, particularly for the development of both mitigation and enhancement strategies (see Brunyé et al., 2020). Despite this, studies have not always considered whether meaningful translations can be made. We suggest that researchers should endeavor to strike the balance between external validity and experimental control (Figure 1), and consider the concept of representative design (Pinder et al., 2011). External validity refers to the transferability of research findings from the research to the target population, whilst representative design refers to methodological approaches chosen to ensure that the experimental task constraints characterize those experienced during performance (i.e., the training or operational environment) (Pinder et al., 2011). Herein, we will focus on representative design during load carriage investigations, due to its mission criticality (Knapik and Reynolds, 2012), and it being the primary physical activity choice during military specific exercise-cognition research. Specifically, we discuss the inclusion of dual-/multi-tasking, implications of study population, cognitive task selection, and the data collection environment.

\section{INCLUSION OF DUAL-/MULTI-TASKING}

The number of tasks presented, and when performance in these tasks is measured is crucial for representative design and external validity respectively. During operations, combatants are required to complete numerous physical and cognitive tasks concurrently; termed dual-/multitasking (Pellecchia, 2005). For example, during load carriage soldiers are required to simultaneously maintain situational awareness, whilst monitoring auditory and visual stimuli (Kobus et al., 2010). This additive effect increases cognitive demands; a result of task demands and the required coordination processes (Son et al., 2019). As such, the ability to manage the interference of, and switching between, conflicting tasks is of high importance during dual-/multi-task performance (Fallahtafti et al., 2020). Failure to do so can result in a performance decrement; termed the dual-task interference effect (Schmidt and Lee, 2013). 
A number of load carriage focused studies, assessing cognitive function, have used a pre-/post-load carriage cognitive assessment methodology (Knapik et al., 1997; Bhattacharyya et al., 2017). Importantly, this pre-/post-load carriage methodology solely provides cognitive performance information at the instance of testing, and not during the load carriage tasks itself. This information during a load carriage task is of particular interest given that such tasks are often protracted in nature (e.g., $30 \mathrm{~min}$ to $18 \mathrm{~h}$; Vine et al., 2017). The importance of within task assessment is evidenced by a number of studies. For example, Eddy et al. (2015), observed an increase in false alarms (auditory go/no-go task) in a loaded ( $40 \mathrm{~kg}$ ) compared to an unloaded condition. However, across six time points, this only occurred in the third, fourth, and fifth. Similarly, Kobus et al. (2010) observed differences in percentage hit rate (detection and identification task) across all assessment time points in each of the three load conditions ( 0 vs. 45.5 vs. $61.2 \mathrm{~kg}$ ). Whilst no pre/post-load carriage comparisons were made in either study, Eddy et al. (2015) observed no difference between load conditions ( 0 vs. $40 \mathrm{~kg}$ ) at either the first or last assessment point, suggesting differences could have been missed had a pre-/post-comparison been used. It has also been suggested that there is often sufficient recovery, post-physical task, for individuals to manage their cognitive resources, enabling the successful completion of the cognitive assessments (Mahoney et al., 2007). Finally, from a representative design perspective, military physical tasks are rarely discrete entities, and are undertaken with numerous interacting constraints and transitions between tasks. Therefore, within task measurements are of far more practical importance than those obtained once the task is complete. Consequently, where possible, it is key that studies undertake a dual-task approach, as they provide both more operationally relevant outcomes and provide greater granularity to the evidence base.

\section{IMPLICATIONS OF STUDY POPULATION}

When considering the transfer of research findings to training and operations considerations should be given to study populations. Military personnel undergo extensive training and rehearsal to be able to execute their missions successfully (Nindl et al., 2013). Through these preparatory efforts, military specific exercise-cognition interaction effects are likely to be positively attenuated as a consequence of cognitive load reduction. Training will beneficially alter combatants' perceptions of factors including physical exertion, comfort, and task difficulty; in turn likely reducing cognitive load. For example, following heat adaptation, an individual's perception of physical exertion and thermal sensation, whilst exercising at high temperatures, are reduced (Tyler et al., 2016). Without this heat adaption, perceived exertion and thermal discomfort would increase, likely leading to irrelevant distractor processing, and a reduction in cognitive function (see Load Theory: Lavie et al., 2004; Lavie, 2010).

The interaction between cognitive assessment selection and study population is also likely to impact the subsequent outcomes, again by altering cognitive load. Specifically, whether the cognitive task completion requires either implicit or explicit processes is likely to impact the magnitude of performance change (Dietrich and Audiffren, 2011). Whilst, the distinction between these processes is greatly contested, and often more complex than assumed (De Houwer and Moors, 2007), broadly, the former relates to automated processing, whilst the latter refers to conscious processing. Therefore, with greater task familiarity, experienced personnel are likely to employ more automated processes compared with a novice, this is turn is likely to reduce the magnitude of possible performance attenuation (Martin et al., 2019). 
Finally, a key critique of the exercise-cognition literature by McMorris (2016) relates to the inadequacies of reporting exercise intensities within studies. Previously, McMorris and Hale (2012), have suggested the use of low $[<40 \%$ maximal oxygen uptake $\left.\left(\mathrm{VO}_{2 \max }\right)\right]$, medium $\left(\geq 40-<80 \% \mathrm{VO}_{2 \max }\right)$, and heavy $(\geq 80 \%$ $\mathrm{VO}_{2 \max }$ ) domains for describing exercise intensities; which were adapted from Borer's (2003) categories. Importantly for exercise-cognition research, these boundaries were designed to coincide with key catecholamine and hypothalamic-pituitaryadrenal axis hormone thresholds. However, training status and testing modality are likely to influence the occurrence of these physiological thresholds relative to maximal capacities (e.g., $\mathrm{VO}_{2 \max }$ or maximum work rate) (Jamnick et al., 2020). Consequently, it appears that the use of physiological parameters, such as ventilatory and lactate thresholds are preferable compared with maximal capacities when describing exercise intensities (e.g., Podolin et al., 1991).

Collectively these factors highlight plausible differences between study populations. It is however important to note that access to military personnel can be difficult. In these cases, careful control of population characteristics (e.g., similar fitness levels) and ensuring thorough familiarization (both to the physical and cognitive tasks, along with clothing and protocols) is imperative for minimizing differences between novice and expert populations, and in turn ensuring the maximum transferability of findings. Moreover, whilst beyond the scope of this piece, it is important to also acknowledge that military performance is fundamentally a result of team performance (Shuffler et al., 2012; Billing et al., 2020), thus additional factors may impact performance outcomes beyond those investigated within individual based research (e.g., group cohesion).

\section{COGNITIVE TASK SELECTION}

When developing representative research paradigms, which aim to enhance transferability of findings, there is a need for clear consideration when selecting cognitive tasks. Within the military-specific exercise-cognition literature a variety of cognitive assessment approaches have been employed; from "basic" non-military specific-assessment (e.g., computer-based work tasks; Knapik et al., 1997; Bhattacharyya et al., 2017) to more externally valid military-specific assessments (e.g., military specific go-/no-go task; Eddy et al., 2015; Giles et al., 2019). With regards to "basic" non-military assessments, these typically isolate individual aspects of cognitive function, which differs from multicomponent requirements placed upon combatants during military operations (Vine et al., 2021). In addition, cognitive task selection is likely to have a direct impact on the magnitude and direction of a performance change. Therefore, it is crucial that the cognitive tasks selected match operational task demands. Moreover, whilst limitations to study size and task selection may exist, Vine et al. (2021) demonstrated poor to no correlation between "basic" and military-specific cognitive assessments. This suggests that either different cognitive processes are being assessed, or more likely, that the complexity of a military task requires numerous cognitive processes to be simultaneously executed. Further cementing the importance of opting for externally valid cognitive assessment methods.

When choosing a cognitive assessment, another factor to consider is the differing exercise-cognition responses for a given type of cognitive assessment. For example, in a metaanalysis by McMorris and Hale (2012), the authors highlighted differing effect sizes for exercise on speed and accuracy focused tasks. Critically, as both parameters are imperative for military operators, it is important to assess both during military-focused research. In addition to this, external validity can be enhanced by selecting cognitive tasks that would be concurrently completed during the physical task of choice. For example, the demands of a visual shoot/don't-shoot (Kobus et al., 2010; Armstrong et al., 2017) or audible go/no-go (Eddy et al., 2015; Armstrong et al., 2017; Giles et al., 2019) task reflect those that would be reasonable to expect during load carriage. Finally, due to the nature of military operations, physical taskings are rarely discrete in nature, but instead form a larger, more varied and often continuous work schedule. Due to repeatability being a limitation of representative design, quantifying the magnitude of both day-to-day and within-day variance, is a critical step in obtaining meaningful data in these scenarios. However, only a single study has reported the variance in performance of military-specific cognitive assessments (Vine et al., 2021). Collectively, these points demonstrate the importance of employing military-specific cognitive assessments in order to ensure the transferability of findings to military operations.

\section{DATA COLLECTION ENVIRONMENT}

Combatants are required to operate effectively under a multitude of environmental constraints (e.g., mountainous, urban) with many of these providing additional challenges for military researchers. However, these additional environment specific stressors, highlight the importance of representative design given the likely interaction between these constraints and cognitive performance. Whilst safety and ethical implications of a "fully" representative military data collection environment make this an impractical approach, more representative designs can still be achieved. At a very simplistic level, soldier's must scan the oncoming terrain for hazards and obstacles in order to identify safe foot locations (Mahoney et al., 2007). This additional competition for cognitive resources, is inherently included within field-based investigations (Crowell et al., 1999; Nibbeling et al., 2014; Giles et al., 2019), but not typically applied during laboratory investigations. This laboratory research omission is despite data demonstrating a reduction in vigilance task performance, and an increase in distance covered by individuals (despite being able to step over them), when walking and avoiding obstacles (Mahoney et al., 2007). Similar results have also been observed when using monocular see-through headmounted displays; whereby a dramatic reduction in a visual monitoring task was observed during walking, but not standing conditions (Mustonen et al., 2013), along with increased response times and reduced accuracy (Sampson, 1993). 
Another consideration is the impact of thermal environmental conditions on cognitive performance (see review by Martin et al., 2019). Despite this comprehensive evidence, only two cognitively focused load carriage investigations have been conducted outside of normothermic conditions (Caldwell et al., 2011; Bhattacharyya et al., 2017). Importantly, many operational environments exist where a combination of environmental conditions may be apparent (e.g., altitude and cold). These conditions may have indirect effects, such as dehydration which has been shown to predict the decrement in central executive tasks and perceptions of mood state during exercise in the heat (McMorris et al., 2006). With both primary and secondary implications of environmental conditions, it emphasizes the importance of this factor within representative design.

Finally, during operations, combatants experience high levels of anxiety due to the constant threat of an enemy attack (Nibbeling et al., 2014). As with the other environmental considerations, the impact of anxiety is additive to the other cognitive challenges. Purportedly, anxiety will result in an attentional shift from task-relevant to task-irrelevant information; likely causing combatants to miss critical information (Nibbeling et al., 2014). Whilst a number of publications have detailed the relationship between anxiety and cognitive performance in police scenarios (e.g., Oudejans, 2008; Nieuwenhuys and Oudejans, 2010, 2011; Nieuwenhuys et al., 2012), considerably less attention has been given within the military sphere (Nibbeling et al., 2014). Again, highlighting

\section{REFERENCES}

Armstrong, N., Doyle, D., Smith, S., Risius, D., Wardle, S., Greeves, J. P., et al. (2017). A preliminary study of the effects of load carriage on cognition during a simulated military task in male and female soldiers. J. Sci. Med. Sport. 20:S125. doi: 10.1016/j.jsams.2017.09.480

Bhattacharyya, D., Pal, M., Chatterjee, T., and Majumdar, D. (2017). Effect of load carriage and natural terrain conditions on cognitive performance in desert environments. Physiol. Behav. 179, 253-261. doi: 10.1016/j.physbeh.2017.06.014

Billing, D. C., Fordy, G. R., Friedl, K. E., and Hasselstrøm, H. (2020). The implications of emerging technology on military human performance research priorities. J. Sci. Med. Sport. doi: 10.1016/j.jsams.2020.10.007. [Epub ahead of print].

Borer, K. T. (2003). Exercise Endocrinology. Champaign, IL: Human Kinetics.

Brunyé, T. T., Brou, R., Doty, T. J., Gregory, F. D., Hussey, E. K., Lieberman, H. R., et al. (2020). A review of US Army research contributing to cognitive enhancement in military contexts. J. Cogn. Enhanc. 4, 1-16. doi: 10.1007/s41465-020-00167-3

Caldwell, J. N., Engelen, L., van der Henst, C., Patterson, M. J., and Taylor, N. A. S. (2011). The interaction of body armor, low-intensity exercise, and hothumid conditions on physiological strain and cognitive function. Mil. Med. 176, 488-493. doi: 10.7205/MILMED-D-10-00010

Chang, Y. K., Labban, J. D., Gapin, J. I., and Etnier, J. L. (2012). The effects of acute exercise on cognitive performance : a meta-analysis. Brain Res. 1453, 87-101. doi: 10.1016/j.brainres.2012.02.068

Crowell, H. P., Krausman, A. S., Harper, W. H., Faughn, J. A., and Sharp, M. A. (1999). Cognitive and Physiological Performance of Soldiers While They Carry Loads Over Various Terrains (Report No.: ARL-TR-1779). Army Research Lab. doi: 10.1037/e445442005-001

De Houwer, J., and Moors, A. (2007). "How to define and examine the implicitness of implicit measures," in Implicit Measures of Attitudes: Procedures and the diversity and prevalence of interacting factors within the battlefield environment that may dramatically influence cognitive performance and further cementing the requirement for representative study designs. Moreover, we suggest, given the similarities between military, non-military uniformed services (e.g., emergency services), and other physically demanding occupations (e.g., mining and energy sectors) this approach should also be utilized with these populations.

\section{CONCLUSION}

With a growing interest in the military-specific exercisecognition relationship, it is key that observations can be translated from a research setting to military training and operations. Whilst some caveats pertaining to representative design exist, we encourage its further use within military research. In particular, we have shown that this can be achieved through an optimized balance between experimental control and external validity for the key parameters of dual-/multitasking, study population, cognitive task selection, and data collection environment.

\section{AUTHOR CONTRIBUTIONS}

CV wrote the initial manuscript draft. CV, SC, SM, SB, and OR then revised the manuscript collaboratively. All authors gave final approval for publication.
Controversies, eds B. Wittenbrink and N. Schwartz (New York, NY: Guilford Press), 179-194.

Dietrich, A., and Audiffren, M. (2011). The reticular-activating hypofrontality (RAH) model of acute exercise. Neurosci. Biobehav. Rev. 35, 1305-1325. doi: 10.1016/j.neubiorev.2011.02.001

Eddy, M. D., Hasselquist, L., Giles, G., Hayes, J. F., Howe, J., Rourke, J., et al. (2015). The effects of load carriage and physical fatigue on cognitive performance. PLoS ONE 10:e0130817. doi: 10.1371/journal.pone.0130817

Fallahtafti, F., Boron, J. B., Venema, D. M., Kim, H. J., and Yentes, J. M. (2020). Task specificity impacts dual-task interference in older adults. Aging Clin. Exp. Res. doi: 10.1007/s40520-020-01575-3. [Epub ahead of print].

Giles, G. E., Hasselquist, L., Caruso, C., and Eddy, M. D. (2019). Load carriage and physical exertion influence cognitive control in military scenarios. Med. Sci. Sports Exerc. 51, 2540-2546. doi: 10.1249/MSS.0000000000002085

Jamnick, N. A., Pettitt, R. W., Granata, C., Pyne, D. B., and Bishop, D. J. (2020). An examination and critique of current methods to determine exercise intensity. Sport. Med. 50, 1729-1756. doi: 10.1007/s40279-020-01322-8

Knapik, J., Ang, P., Meiselman, H., Johnson, W., Kirk, J., Bensel, C., et al. (1997) Soldier performance and strenuous road marching: influence of load mass and load distribution. Mil. Med. 162, 62-67. doi: 10.1093/milmed/162.1.62

Knapik, J., and Reynolds, K. (2012). "Load carriage in military operations: a review of historical, physiological, biomechanical and medical aspects," in Military Quantitative Physiology: Problems and Concepts in Military Operational Medicine, ed W. R. Santee and K. E. Friedl (Fort Detrick, MD: Office of the Surgeon General and the Borden Institute), 303-337.

Kobus, D. A., Brown, C. M., Wu, L., Robusto, K., and Bartlett, J. (2010). Cognitive Performance and Physiological Changes Under Heavy Load Carriage (Report No. 10-12). Pacific Science and Engineering Group Inc. doi: 10.21236/ADA 551468

Lambourne, K., and Tomporowski, P. (2010). The effect of exercise-induced arousal on cognitive task performance: a meta-regression analysis. Brain Res. 1341, 12-24. doi: 10.1016/j.brainres.2010.03.091 
Lavie, N. (2010). Attention, distraction, and cognitive control under load. Curr. Dir. Psychol. Sci. 19, 143-148. doi: 10.1177/0963721410370295

Lavie, N., Hirst, A., De Fockert, J. W., and Viding, E. (2004). Load theory of selective attention and cognitive control. J. Exp. Psychol. Gen. 133:339. doi: 10.1037/0096-3445.133.3.339

Mahoney, C. R., Hirsch, E., Hasselquist, L., Lesher, L. L., and Lieberman, H. R. (2007). The effects of movement and physical exertion on soldier vigilance. Aviat. Space Environ. Med. 78, B51-B57.

Martin, K., McLeod, E., Périard, J., Rattray, B., Keegan, R., and Pyne, D. B. (2019). The impact of environmental stress on cognitive performance: a systematic review. Hum. Factors 61, 1205-1246. doi: 10.1177/0018720819839817

May, B., Tomporowski, P. D., and Ferrara, M. (2009). Effects of backpack load on balance and decisional processes. Mil. Med. 174, 1308-1312. doi: 10.7205/MILMED-D-00-0809

McMorris, T. (2016). "History of research into the acute exercise-cognition interaction: A cognitive psychology approach," in Exercise-Cognition Interaction: Neuroscience Perspectives, ed T. McMorris (Cambridge, MA: Elsevier Academic Press), 1-28. doi: 10.1016/B978-0-12-800778-5.00001-3

McMorris, T., and Hale, B. J. (2012). Differential effects of differing intensities of acute exercise on speed and accuracy of cognition: a meta-analytical investigation. Brain. Cogn. 80, 338-351. doi: 10.1016/j.bandc.2012.09.001

McMorris, T., Swain, J., Smith, M., Corbett, J., Delves, S., Sale, C., et al. (2006). Heat stress, plasma concentrations of adrenaline, noradrenaline, 5hydroxytryptamine and cortisol, mood state and cognitive performance. Int. J. Psychophysiol. 61, 204-215. doi: 10.1016/j.ijpsycho.2005.10.002

Mustonen, T., Berg, M., Kaistinen, J., Kawai, T., and Häkkinen, J. (2013). Visual task performance using a monocular see-through head-mounted display (HMD) while walking. J. Exp. Psychol. Appl. 19:333. doi: 10.1037/a0034635

Nibbeling, N., Oudejans, R. R. D., Ubink, E. M., and Daanen, H. A. M. (2014). The effects of anxiety and exercise-induced fatigue on shooting accuracy and cognitive performance in infantry soldiers. Ergonomics 57, 1366-1379. doi: $10.1080 / 00140139.2014 .924572$

Nieuwenhuys, A., and Oudejans, R. R. D. (2010). Effects of anxiety on handgun shooting behavior of police officers: a pilot study. Anxiety Stress Coping 23, 225-233. doi: $10.1080 / 10615800902977494$

Nieuwenhuys, A., and Oudejans, R. R. D. (2011). Training with anxiety: short-and long-term effects on police officers' shooting behavior under pressure. Cogn. Process. 12, 277-288. doi: 10.1007/s10339-011-0396-x

Nieuwenhuys, A., Savelsbergh, G. J. P., and Oudejans, R. R. D. (2012). Shoot or don't shoot? Why police officers are more inclined to shoot when they are anxious. Emotion 12, 827-833. doi: 10.1037/a0025699

Nindl, B. C., Castellani, J. W., Warr, B. J., Sharp, M. A., Henning, P. C., Spiering, B. A., et al. (2013). Physiological Employment Standards III: physiological challenges and consequences encountered during international military deployments. Eur. J. Appl. Physiol. 113, 2655-2672. doi: 10.1007/s00421-013-2591-1

Oudejans, R. R. D. (2008). Reality-based practice under pressure improves handgun shooting performance of police officers. Ergonomics 51, 261-273. doi: $10.1080 / 00140130701577435$

Pellecchia, G. L. (2005). Dual-task training reduces impact of cognitive task on postural sway. J. Mot. Behav. 37, 239-246. doi: 10.3200/JMBR.37.3.239-246
Pinder, R. A., Davids, K., Renshaw, I., and Araújo, D. (2011). Representative learning design and functionality of research and practice in sport. J. Sport Exerc. Psychol. 33, 146-155. doi: 10.1123/jsep.33.1.146

Podolin, D. A., Munger, P. A., and Mazzeo, R. S. (1991). Plasma catecholamine and lactate response during graded exercise with varied glycogen conditions. J. Appl. Physiol. 71, 1427-1433. doi: 10.1152/jappl.1991.71.4.1427

Roberts, A. P. J., and Cole, J. C. (2013). The effects of exercise and body armor on cognitive function in healthy volunteers. Mil. Med. 178, 479-486. doi: 10.7205/MILMED-D-12-00385

Russo, M., McGhee, J., Friedler, E., and Thomas, M. (2005). "Cognitive performance in operational environments," in Strategies to Maintain Combat Readiness During Extended Deployments-A Human Systems Approach (Neuilly-sur-Seine: RTO), 14-1-14-16. Meeting Proceedings.

Sampson, J. B. (1993). "Cognitive performance of individuals using a headmounted display while walking," in Proceedings of the Human Factors and Ergonomics Society Annual Meeting (Los Angeles, CA: SAGE Publications), 338-342. Meeting Proceedings. doi: 10.1177/154193129303700418

Schmidt, R. A., and Lee, T. D. (2013). Motor Learning and Performance: From Principles to Application, 5th Edn. Champaign, IL: Human Kinetics.

Shuffler, M. L., Pavlas, D., and Salas, E. (2012). "Teams in the military," in Oxford Handbook of Miltary Psychology, eds J. H. Laurence and M. D. Matthews (Oxford: Oxford University Press), 282-310. doi: 10.1093/oxfordhb/9780195399325.013.0106

Son, M., Hyun, S., Beck, D., Jung, J., and Park, W. (2019). Effects of backpack weight on the performance of basic short-term/working memory tasks during flat-surface standing. Ergonomics 62, 548-564. doi: 10.1080/00140139.2019.1576924

Tyler, C. J., Reeve, T., Hodges, G. J., and Cheung, S. S. (2016). The effects of heat adaptation on physiology, perception and exercise performance in the heat: a meta-analysis. Sport. Med. 46, 1699-1724. doi: 10.1007/s40279-0160538-5

Vine, C. A. J., Coakley, S. L., Myers, S. D., Blacker, S. D., and Runswick, O. R. (2021). The reliability of a military specific auditory $N$-back task and shoot/don'tshoot task. Available online at: psyarxiv.com/89vb5 (accessed February 5, 2021). doi: 10.31234/osf.io/89vb5

Vine, C. A. J., Myers, S. D., Walker, E. F., Coakley, S. L., Rue, C. A., Lee, B. J., et al. (2017). A job task analysis to quantify the physical demands of load carriage duties conducted by ground close combat roles in the UK Armed Forces. J. Sci. Med. Sport 20, S64-S65. doi: 10.1016/j.jsams.2017.09.121

Conflict of Interest: The authors declare that the research was conducted in the absence of any commercial or financial relationships that could be construed as a potential conflict of interest.

Copyright (๑ 2021 Vine, Myers, Coakley, Blacker and Runswick. This is an openaccess article distributed under the terms of the Creative Commons Attribution License (CC BY). The use, distribution or reproduction in other forums is permitted, provided the original author(s) and the copyright owner(s) are credited and that the original publication in this journal is cited, in accordance with accepted academic practice. No use, distribution or reproduction is permitted which does not comply with these terms. 